\title{
ANALISIS ANTRIAN PELAYANAN NASABAH PADA PT BANK SYARIAH MANDIRI CABANG BUNGKU
}

\author{
HILDA \\ SAHARUDDIN KASENG \\ HUSEIN HI. MOH. SALEH \\ Program Studi S1 Manajemen Fakultas Ekonomi Universitas Tadulako \\ Email: hildaidahilda@gmail.com
}

\begin{abstract}
ABSTRACK
This study aims to analiyzethe system of optimal service queue at the teller that existed in PT BankSyariah Mandiri Bungku Branch. The analytical method used is M/M/1 or single channel singlephase, but to compare the optimal or not the queue of customer service at PT Bank Syariah Mandiribranch when adding one teller in solid time so the used M/M/S analysis method or multi channelsingle phase. The result of analysis by using one teller in cash deposit of solid time is probability insystem is equal to 0,0572 . The teller utility level is 0,94 or $94 \%$ the average number of customers inthe system is 17 people, while using two tellers can be seen the probability in the system is 0,350 or noone in the system. Teller utility rate is reduced to 0,48 or $48 \%$ of the average number of customers inthe system is 1 person, it indicates that the customer queuing in the system is optimal. Based on thedata is can be concluded that the addition of one teller at a solid time can optimize the existingservices in PT Bnk Syariah Mandiri Bungku branc.
\end{abstract}

Keywords: Queue System, Optimal.

\section{ABSTRAK}

Penelitian ini bertujuan untuk menganalisis sistem antrian pelayanan yang optimal pada bagianteller yang ada pada PT Bank Syariah Mandiri Cabang Bungku. Metode analisis yang digunakanadalah M/M/1 atau Single Channel Single Phase, tetapi untuk membandingkan optimal atau tidaknyaantrian pelayanan nasabah pada PT Bank Syariah Mandiri Cabang Bungku apabila menambahkansatu teller pada waktu padat sehingga digunakan metode analisis M/M/S atau Multi Channel SinglePhase. Hasil analisis dengan menggunakan satu teller pada penyetoran tunai waktu padat adalahprobabilitas dalam sistem adalah sebesar 0,0572. Tingkat utilitas teller adalah 0,94 atau $94 \%$, jumlahnasabah rata-rata dalam sistem adalah 17 orang, sedangkan dengan menggunakan dua teller dapatdilihat probabilitas dalam sistem adalah 0,350 atau tidak ada orang dalam sistem. Tingkat utilitas tellerberkurang menjadi 0,48 atau $48 \%$, jumlah rata-rata nasabah dalam sistem adalah 1 orang, inimenunjukkan bahwa nasabah yang mengantri dalam sistem sudah optimal. Berdasarkan data tersebutdapat disimpulkan bahwa penambahan satu teller pada waktu padat dapat mengoptimalkan pelayananyang ada pada PT Bank Syariah Mandiri Cabang Bungku.

Kata Kunci: Sistem Antrian, Optimal.

\section{PENDAHULUAN}

Antrian merupakan kegiatan yang sering kali dijumpai bukan hanya pada kegiatan-kegiatan komersil, pusat pemerintahan, bahkan antrian kini dapat dijumpai pada kantor-kantor layananmasyarakat, seperti antrian di pusat perbelanjaan, antrian di bank, dan lain-lain. Antrian terjadi ketikajumlah nasabah yang dilayani melebihi kapasitas layanan yang tersedia.

Antrian yang panjang dapat merugikan pihak yang membutuhkan pelayanan, karena banyaknya waktu terbuang selama menunggu. Pihak pemberi pelayanan secara tidak langsung juga mengalamikerugian, karena akan mengurangi efisiensi kerja, keuntungan yang sedikit, bahkan bisa menimbulkancitra kurang baik pada nasabahnya. Jika dapat diketahui kedatangan nasabah sebelumnya,pengoperasian sarana dapat dijadwalkan sedemikian rupa sehingga dapat mengantisipasi kedatangannasabah agar tidak lama menunggu. Nasabah akan dilayani dengan laju layanan yang konstan ataubervariasi dan akhirnya meninggalkan sistem. 
Menurut Gross dan Haris (1994), sistem antrian adalah kedatangan pelanggan untuk mendapatkanpelayanan, menunggu untuk dilayani jika fasilitas pelayanan masih sibuk, setelah mendapatkanpelayanan kemudian meninggalkan sistem setelah dilayani. Kegiatan antrian tampak ditemukan dalamfasilitas-fasilitas pelayanan umum, salah satunya pada perbankan.

PT Bank Syariah Mandiri Cabang Bungku merupakan perusahaan yang berlokasi di KelurahanMatansala, Kecamatan Bungku Tengah, Kabupaten Morowali. PT Bank Syariah Mandiri CabangBungku memiliki satu counter teller yang ditempatkan pada sistem antrian dan bertugas untukmelayani para nasabah yang akan melakukan transaksi penyetoran tunai, penarikan tunai, dan transferuang. Banyaknya jumlah nasabah yang ada dalam antrian tidak seimbang dengan jumlah teller yangmelayani nasabah, hal ini mengakibatkan terjadinya penumpukan antrian pada teller bagian depanyang cukup banyak sehingga nasabah membutuhkan cukup waktu lama untuk menunggu giliran agarmendapatkan pelayanan.

Sistem antrian yang diterapkan di PT Bank Syariah Mandiri Cabang Bungku menggunakan modelsistem antrian Single Channel Single Phase dimana terdapat satu teller yang melayani nasabah namunnasabah hanya perlu melewati satu tahap pelayanan saja. PT Bank Syariah Mandiri Cabang Bungkutidak memberikan nomor antrian pada nasabah melainkan nasabah yang datang langsung mengisi slipdan duduk di kursi tunggu yang telah tersedia sambil menunggu giliran untuk dilayani oleh teller.

\section{KAJIAN LITERATURE DAN PENGEMBANGAN HIPOTESIS}

\section{Penelitian Terdahulu}

Penelitian terdahulu, digunakan untuk menyelesaikan masalah antrian dengan mengubah sistemantrian yang sudah ada sebelumnya. Penelitian yang dilakukan oleh Prabowo dan Bodroastuti (2012),yang berjudul “ Penentuan Jumlah Teller yang Optimal” hasil penelitian menunjukkan bahwa adanyapenurunan waktu tunggu dari 22 menit 2 detik menjadi 5 menit 16 detik dengan penambahan 5 telleryang semula dari 2 teller.

Penelitian yang dilakukan oleh Wahyudi (2010), dari Universitas Islam Negeri Sunan Kalijagatentang "Penerapan Model Antrian Dua fase", menganalisis sistem antrian di Rumah Sakit MataDr.Yap Yogyakarta. Hasil penelitian didapatkan bahwa sistem antrian pada Rumah Sakit Dr.YapYogyakarta telah efektif .

Berikut penelitian terdahulu yang dilakukan oleh Rustam Taufik (2012) tentang "AnalisisPenerapan Sistem Antrian Model Multi Channel Single Phase (M/M/S) Pada PT Bank NegaraIndonesia Kantor Cabang Pembantu Universitas Hasanuddin Makassar". Tujuan penelitian ini adalahuntuk mengetahui kinerja sistem antrian yang saat ini diaplikasikan pada PT Bank Negara IndonesiaKantor Cabang Pembantu Universitas Hasanuddin Makassar. Berdasarkan hasil penelitian, jenispenelitian yang digunakan adalah jenis sistem antrian model Multi Channel Single Phase atau M/M/S,dimana terdapat beberapa teller yang dapat melayani para nasabah namun fase yang dilewati nasabahuntuk melakukan transaksi melalui teller hanya satu kali. Hasil perhitungan kinerja sistem antrian padaPT Bank Negara Indonesia Kantor Cabang Pembantu Universitas Hasanuddin Makassar, waktuterpanjang yang dibutuhkan seorang nasabah dalam antrian hanya selama 2,2366 menit serta antrianterpanjang hanya sebanyak 2,3875 orang dan ini terjadi hanya pada periode waktu jam 10.00-11.00setiap harinya.

\section{Teori Antrian}

Menurut Sinalungga (2008) teori antrian (Queueing Theory) merupakan studi probabilistik kejadiangaris tunggu (waiting lines), yakni suatu garis tunggu dari pelanggan yang memerlukan layanan darisistem yang ada. Antrian terjadi karena adanya keterbatasan sumber pelayanan, yang umumnyaberkaitan dengan terbatasnya pelayanan karena alasan ekonomi. Jika jumlah channel yang disediakanterbatas, memungkinkan terjadi antrian yang terlalu lama, sehingga orang dapat memutuskan untuk 
meninggalkan antrian tersebut. Antrian yang sangat panjang dan terlalu lama untuk memperolehgiliran pelayanan sangatlah menjengkelkan. Rata-rata lamanya waktu menunggu (waiting time) sangattergantung kepada rata-rata tingkat kecepatan pelayanan (rate of services).

Teori tentang antrian ditemukan dan dikembangkan oleh Erlang, seorang Insinyur dari Denmarkyang bekerja pada perusahaan telepon di Kopenhagen pada tahun 1910, Erlang melakukan eksperimententang fluktuasi permintaan fasilitas telepon yang berhubungan dengan automatic dialing equipment,yaitu peralatan penyambungan telepon secara otomatis. Operator sangat kewalahan untuk melayanipara penelepon secepatnya pada waktu-waktu yang sibuk, sehingga para penelepon harus antrimenunggu giliran, mungkin cukup lama. Persoalan aslinya Erlang hanya melakukan perhitunganketerlambatan (delay) dari seorang operator, kemudian pada tahun 1917 penelitian dilanjutkan untukmenghitung kesibukan beberapa operator. Antrian adalah suatu garis tunggu dari nasabah yangmemerlukan layanan dari satu atau lebih fasilitas pelayanan (Siagian, 1987). Sistem antrian dapatdiklasifikasikan menjadi sistem yang berbeda-beda dimana teori antrian dan simulasi sering diterapkansecara luas.

\section{Komponen Dasar Dalam Proses Antrian}

Sistem antrian bergantung pada 7 (tujuh) komponen yaitu pola kedatangan, pola kepergian,kapasitas sistem, desain pelayanan, disiplin pelayanan, ukuran sumber pemanggilan, dan perilakumanusia (Taha, 1996). Menurut Heizer dan Berry (2005) terdapat tiga komponen dalam sebuah sistemantrian, yaitu:

\section{Pola Kedatangan}

Menurut Wagner (1972) pola kedatangan adalah pola pembentukan antrian akibatkedatangan customer dalam selang waktu tertentu. Pola kedatangan dapat diketahui secara pasti atauberupa suatu variabel acak yang distribusi peluangnya dianggap telah diketahui, jika tidak disebutkansecara khusus customer datang secara individu kedalam sistem antrian, namun dapat pula lebih darisatu customer datang secara bersamaan kedalam sistem antrian.

\section{Pola Kepergian}

Pola kepergian adalah banyak kepergian pelanggan selama periode waktu tertentu. Pola kepergianbiasanya dicirikan oleh waktu pelayanan, yaitu waktu yang dibutuhkan oleh seorang pelayan untukmelayani seorang pelanggan. Waktu pelayanan dapat bersifat deterministik dan dapat berupa suatuvariabel acak dengan distribusi peluang tertentu (Bronson,1996). Waktu pelayanan bersifatdeterministik berarti bahwa waktu yang dibutuhkan untuk melayani setiap pelanggan selalu tetap,sedangkan waktu pelayanan yang berupa variabel acak adalah waktu yang dibutuhkan untuk melayanisetiap pelanggan berbeda-beda.

\section{Kapasitas Sistem}

Menurut Bronson (1996) kapasitas sistem adalah banyak maksimum pelanggan,baik pelanggan yang sedang berada dalam pelayanan maupun dalam antrian yang ditampung olehfasilitas pelayanan pada waktu yang sama. Sistem antrian yang tidak membatasibanyak pelanggan dalam fasilitas pelayanannya disebut sistem berkapasitas tak berhingga, sedangkansuatu sistem yang membatasi banyak pelanggan dalam fasilitas pelayanannya disebut sistemberkapasitas berhingga, jika pelanggan memasuki sistem pada saat fasilitas pelayanan penuhmaka pelanggan akan ditolak dan meninggalkan sistem tanpa memperoleh pelayanan.

\section{Desain Pelayanan}

Menurut Sinalungga (2008) desain pelayanan dapat diklasifikasikan dalam channel dan phase yangakan membentuk suatu struktur antrian yang berbeda-beda. Channel menunjukkan jumlah jalur untuk 
memasuki sistem pelayanan. Phase berarti jumlah stasiun-stasiun pelayanan, dimana para pelangganharus melaluinya sebelum pelayanan dinyatakan lengkap.

\section{Disiplin Pelayanan}

Disiplin antrian dikolompokan menjadi dua, yaitu preemptive dan non preemptive . Disiplinpreemptive menggambarkan situasi dimana pelayanan sedang melayani seseorang, kemudian beralihmelayani orang yang diprioritaskan meskipun belum selesai melayani orang sebelumnya. SementaraDisiplin non preemptive menggambarkan dimana situasi pelayan akan menyelesaikan pelayanannyakemudian beralih melayani orang yang diprioritaskan. Menurut Sinalungga (2008) disiplin pelayananadalah suatu aturan yang dikenalkan dalam memilih pelanggan dari barisan antrian untuk segeradilayani. Adapun pembagian disiplin pelayananan ialah:

First Come First Served (FCFS) atau First In First Out (FIFO)

Suatu pearaturan dimana yang akan dilayani adalah pelanggan yang datang terlebih dahulu. Bilaada pelanggan yang datang pada waktu yang sama, maka pelayanan pelanggan dilakukan melaluiurutan pelanggan dalam antrian. Proses antrian yang di belakang harus menunggu sampai semuaproses di depannya selesai. Setiap proses yang berada pada status ready dimasukan ke dalam FCFSqueue sesuai dengan waktu kedatangan. Contohnya antrian disuatu kasir sebuah swalayan.

Last Come First Served atau Last In First Out (LIFO)

Last come first served atau last in first out (FIFO) merupakan disiplin antrian dimana yang datangpaling akhir adalah yang dilayani paling awal atau paling dahulu. Contoh antrian pada satu tumpukanbarang di gudang, barang yang terakhir masuk akan berada ditunpukan paling atas sehingga diambilpertama.

Service In Random Order (SIRO) atau Pelayanan Dalam Urutan

Acak atau sering dikenal juga Random Selection For Services (RSFS), artinya pelayanan atau panggilan didasarkan pada peluang secara random, tidak mempermasalahkan siapa yang lebih dahulutiba. Contohnya kertas-kertas undian yang menunggu untuk ditentukan pemenangnya, yang diambilsecara acak.

Priority Service (PS),

Kepada orang yang mempunyai prioritas paling tinggi dibandingkan dengan orang yang memilikiprioritas paling rendah, meskipun yang terakhir ini sudah lebih dahulu tiba dalam garis tunggu. Kejadian seperti ini bisa disebabkan oleh beberapa hal, misalnya seseorang yang keadaan penyakityang lebih berat dibanding dengan orang lain dalam sebuah rumah sakit.

\section{Sumber Pemanggilan}

Menurut Taha (1996) ukuran sumber pemanggilan adalah banyaknya populasi yang membutuhkanpelayanan dalam suatu sistem antrian, ukuran sumber pemanggilan dapat terbatas maupun tidakterbatas. Sumber pemanggilan terbatas misalnya mahasiswa yang akan melakukan registrasi ulangdisuatu Universitas, dimana jumlahnya sudah pasti. Sumber pemanggilan yang tidak terbatas misalnyanasabah bank yang antri untuk menabung atau membuka rekening baru, jumlahnya bisa tidak terbatas.

\section{Perilaku Manusia}

Perilaku manusia merupakan perilaku yang mempengaruhi suatu sistem antrian ketika manusiamempunyai peran dalam sistem baik sebagai customer maupun pelayan. Jika manusia berperansebagai pelayan, dapat melayani customer dengan cepat atau lambat sesuai kemampuannya sehinggamempengaruhi lamanya waktu tunggu (Taha, 1996). Menurut Gross dan Harris (1998) perilakumanusia dalam sistem antrian jika berperan sebagai customer sebagai berikut: 
a. Reneging menggambarkan situasi dimana seseorang masuk dalam antrian, namun belum memperoleh pelayanan, kemudian meninggalkan antrian tersebut.

b. Balking menggambarkan orang yang tidak masuk dalam antrian dan langsung meninggalkan tempat antrian.

c. Jockeying, menggambarkan situasi jika dalam sistem ada dua atau lebih jalur antrian maka orang dapat berpindah antrian dari jalur yang satu ke jalur yang lain.

Model Struktur Antrian

Single Channel Single Phase

Single Channel berarti bahwa hanya ada satu jalur untuk memasuki sistem pelayanan atau ada satupelayanan. Single Phase menunjukkan bahwa hanya ada satu stasiun pelayanan sehingga yang telahmenerima pelayanan dapat langsung keluar dari sistem antrian. Contohnya antrian pada penjualankarcis kereta api yang hanya dibuka satu loket. Sistem antrian Single Channel Single Phase.

Single Channel Multi Phase

Struktur ini memiliki satu jalur pelayanan sehingga disebut Single Channel. Istilah Multi Phasemenunjukkan ada dua atau lebih pelayanan yang dilaksanakan secara berurutan. Misalnya pada antriandi laundry, pakaian-pakaian setelah dicuci kemudian dijemur lalu disetrika dan terakhir dikemas.

Multi Channel Single Phase

Sistem Multi Channel Single Phase terjadi ketika dua atau lebih fasilitas pelayanan dialiri olehantrian tunggal. Sistem ini memiliki lebih dari satu jalur pelayanan atau fasilitas pelayanan sedangkansistem pelayanannya hanya ada satu phase. Contoh: pelayanan disuatu bank yang dilayani olehbeberapa teller Multi Channel Multi Phase

Sistem ini terjadi jika ada dua atau lebih fasilitas pelayanan dengan pelayanannya lebih darisatu phase. Sebagai contoh adalah pelayanan kepada pasien di rumah sakit dari pendaftaran, diagnosa,tindakan medis sampai pembayaran. Setiap sistem-sistem ini mempunyai beberapa fasilitas pelayananpada setiap tahap, sehingga lebih dari satu individu dapat dilayani pada suatu waktu.

\section{METODE PENELITIAN}

\section{Jenis Penelitian}

Jenis penelitian ini menggunakan tipe penelitian deskripsi. Penelitian deskriptif adalah penelitianyang dilakukan dengan tujuan untuk memberikan gambaran atau deskripsi tentang suatu keadaan, datayang sebenarnya dengan fakta tentang antrian pelayanan pada PT Bank Syariah Mandiri CabangBungku.

\section{Lokasi Penelitian}

Adapun lokasi penelitian ini dilakukan pada PT Bank Syariah Mandiri Cabang Bungku yang terletak di Kelurahan Matansala, Kecamatan Bungku Tengah, Kabupaten Morowali. Alasanmelakukan penelitian disini karna jumlah kedatangan nasabah pada waktu padat lebih banyak daripadajumlah fasilitas pelayanan terutama pada bagian teller sehingga banyak nasabah yang mengantri untukmendapat pelayanan.

\section{Sumber Data}

Data adalah segala sesuatu yang diketahui atau dianggap mempunyai sifat bisa memberikangambaran tentang suatu keadaan atau persoalan. Jenis data yang digunakan dalam penelitian inimeliputi data primer dan sekunder. Data primer merupakan data yang diperoleh secara langsung darisumber asli tanpa melalui perantara. Data primer yang ada dalam penelitian ini merupakan datamentah yang diperoleh dari hasil pengamatan langsung tentang variabel-variabel sistem antrian padaPT Bank Syariah Mandiri Cabang Bungku. Data sekunder adalah data yang telah tersusun dalam 
bentuk dokumen-dokumen tertulis yang diperoleh dari bahan pustaka buku-buku, serta literatur-literatur lainnya yang terkait dalam penelitian dan internet. Data tersebut seperti panjang antrian,waktu tunggu antrian, serta menganalisis waktu yang optimal untuk melayani para nasabah agar tidakterlalu lama menunggu dan menentukan jumlah teller yang optimal pada saat jam sibuk pelayanan.

Populasi

Populasi adalah keseluruhan nilai yang mungkin, hasil pengukuran ataupun perhitungan, kualitatifmaupun kuantitatif mengenai karakter tertentu dari semua anggota kumpulan yang lengkap dan jelasyang ingin dipelajari sifat-sifatnya. Populasi yang digunakan dalam penelitian ini adalah nasabah yangmelakukan penyetoran tunai pada PT Bank Syariah Mandiri Cabang Bungku khususnya pada waktupadat.

\section{Metode Pengumpulan Data}

\section{Wawancara}

Wawancara sebagai teknik pencarian dan pengumpulan informasi dilakukan dengan mendatangisecara langsung kepada responden untuk dimintai keterangan mengenai sesuatu yang diketahui(bisa mengenai suatu kejadian, fakta, maupun pendapat responden). Wawancara ini diperoleh daripihak PT Bank Syariah Mandiri Cabang Bungku, Kabupaten Morowali.

\section{Observasi}

Observasi adalah Proses pengamatan dan pencatatan secara sistematis mengenai gejala-gejala yangditeliti. Observasi ini menjadi salah satu dari teknik pengumpulan data apabila sesuai dengantujuan penelitian, yang direncanakan dan dicatat secara sistematis, serta dapat dikontrol keandalan(reliabilitas) dan kesahihannya (validitasnya). Pengamatan ini langsung penulis lakukan dilapangan dengan menggunakan stopwatch.

\section{Studi Pustaka}

Pengumpulan data yang dilakukan dengan membaca buku-buku literatur, jurnal, internet, majalah,dan penelitian terdahulu yang berkaitan dengan penelitian yang sedang dilakukan. Penelitian inimelakukan pengamatan jarak jauh dengan mengukur kecepatan kedatangan nasabah serta lamapelayanan yang diterimanya pada setiap teller dengan menggunakan stopwatch.

\section{Metode Analisis Data}

Analisis data kedatangan nasabah diolah dengan frekuensi interval waktu 1 jam atau 60 menit untuk mencari jumlah kedatangan orang persatuan waktu $(\lambda)$. Data pelayanan nasabahdituangkan kedalam distribusi frekuensi guna mencari jumlah frekuensi pelayanan yaitujumlah rata-rata orang yang dilayani persatuan waktu $(\mu)$. Adapun rumus yang digunakanadalah:

Model antrian yang digunakan untuk melayani nasabah yakni pada proses transaksi di PT BankSyariah Mandiri Cabang Bungku menggunakan model antrian jalur tunggal artinya terdapat satu teller(layanan) yang melayani para nasabah, dan hanya satu tahap pelayanan (phase) yang harus dilalui olehnasabah untuk menyelesaikan transaksi.

Disiplin antrian PT Bank Syariah Mandiri Cabang Bungku menerapkan First Come First Serveddimana nasabah yang datang pertama akan dilayani terlebih dahulu. Sistem transaksi pada PT BankSyariah Mandiri Cabang Bungku adalah model jalur tunggal maka proses transaksi dapat digunakanModel M/M/1 ( Single Channel Single Phase). 


\section{HASIL DAN PEMBAHASAN}

Analisis Antrian Dengan Menggunakan Model Single Channel Single Phase (M/M/1) Pada Waktu Padat

Model antrian Singel Cahnnel Single Phase (M/M/1) merupakan model antrian jalur tunggalartinya kedatangan membentuk satu jalur tunggal untuk memasuki sistem pelayanan dan hanya adasatu stasiun pelayanan yang disediakan. Model antrian ini digunakan pada bagian teller di PT BankSyariah Mandiri Cabang Bungku. Berdasarkan hasil penelitian yang dilakukakan khususnya padabagian teller hanya terdapat satu pelayanan yang disediakan untuk melayani para nasabah, sehinggapenulis dapat menganalisis dengan menggunakan model Single Channel Single Phase (M/M/1).

Berikut tabel hasil perhitungan dengan menggunakan model Single Channel Single Phase (M/M/1).

Tabel 1

Hasil Sistem Antrian Dengan Satu Teller

\begin{tabular}{|c|c|c|c|c|c|c|c|c|}
\hline \multirow{2}{*}{ No } & \multirow{2}{*}{ Hari } & Tanggal & \multicolumn{7}{|c|}{ Kinerja Sistem Antrian } \\
\cline { 4 - 9 } 1 & Rabu & 01 November 2017 & 0,1471 & 0,85 & 5,8 & 0,2 & 4,947 & 0,127 \\
2 & Kamis & 02 November 2017 & 0,3158 & 0,68 & 2,17 & 0,083 & 1,482 & 0,057 \\
3 & Jumat & 03 November 2017 & 0,2433 & 0,75 & 3,11 & 0,111 & 2,354 & 0,084 \\
4 & Senin & 06 November 2017 & 0,0572 & 0,94 & 16,5 & 0,5 & 15,6 & 0,4714 \\
\hline
\end{tabular}

Sumber: Data hasil perhitungan

Berdasarkan Tabel 1 terlihat bahwa:

Tingkat utilitas teller atau tingkat kesibukan teller (p)

Waktu sibuk teller adalah pada hari Senin tanggal 6 November 2017 dimana terlihat pada harisenin tingkat utilitas atau kesibukan teller sebesar 0,94 atau 94\%, ini menunjukkan bahwa tingkatkesibukan teller sangat tinggi mencapai $94 \%$ atau masih belum optimal, karena sedikitnya waktumenganggur teller yaitu hanya 6\% sehingga perlu menambahkan satu teller pada waktu padat agarada keseimbangan antara nasabah yang datang dengan teller yang melayani.

Rata-rata jumlah nasabah dalam antrian (Lq)

Rata-rata jumlah nasabah dalam antrian terpanjang terjadi pada periode hari Senin dimana terlihatrata-rata nasabah yang mengantri pada hari tersebut sebanyak 15 orang, ini menunjukkan bahwa masihbanyak nasabah dalam antrian yang menunggu untuk dilayani. Sedangkan jumlah rata-rata nasabahdalam antrian terpendek terjadi pada hari Kamis tanggal 02 November 2017 dimana yang mengantrisebanyak 1 orang khusus waktu padat, ini menunjukkan bahwa jumlah orang menunggu untukdilayani sudah optimal karena tidak ada satupun nasabah lain yang menunggu untuk dilayani.

Rata-rata jumlah nasabah dalam sistem (Ls)

Rata-rata jumlah nasabah yang menunggu dalam sistem terpanjang terjadi pada hari Senin dimanajumlah nasabah yang menunggu dalam sistem sebanyak 16 orang, ini menunjukkan bahwa banyaknasabah yang mengantri dalam sistem dan masih belum optimal karena 16 orang nasabah yang adadalam sistem. Sedangkan jumlah rata-rata nasabah yang menunggu dalam sistem terpendek terjadipada hari Kamis tanggal 02 November 2017 yaitu sebanyak 2 orang, ini menunjukkan bahwa nasabahyang mengantri dalam sistem hanya sebanyak 2 orang dan sudah optimal. 
Waktu rata-rata yang dihabiskan oleh seorang nasabah untuk menunggu dalam antrian(Wq)

Waktu terpanjang yang diperlukan nasabah dalam antrian adalah 0,4714 jam atau 28 menit 16detik, ini terjadi pada hari Senin 06 November 2017 dan ini masih belum optimal karena waktu yangdiperlukan nasabah dalam antrian cukup lama. Sedangkan waktu terpendek adalah selama 0,057 jamatau 3 menit 25 detik ini terjadi pada hari Kamis 02 November 2017 dan ini sudah optimal.

Waktu rata-rata yang dihabiskan seorang nasabah dalam sistem (Ws)

Waktu terpanjang yang dihabiskan seorang dalam sistem adalah selama 0,5 jam atau 30 menit 28detik ini terjadi hari Senin 06 November 2017 dan ini menunjukkan masih belum optimal karenawaktu yang dihabiskan nasabah dalam sistem cukup lama yaitu selama 30 menit 28 detik. Sedangkanwaktu terpendek adalah selama 0,083 jam atau 4 menit 58 detik terjadi pada hari Kamis 02 November2017 ini menunjukkan bahwa waktu yang dihabiskan nasabah dalam sistem sudah tidak terlalu lamahanya selama 4 menit 58 detik dan sudah optimal.

Berdasarkan penjelasan di atas maka dapat disimpulkan bahwa kinerja sistem antrian pada PTBank Syariah Mandiri Cabang Bungku dengan menggunakan satu teller masih belum optimal karenawaktu terpanjang yang dibutuhkan seorang nasabah dalam antrian adalah sebanyak 0,4714 jam atau28 menit 16 detik serta antrian terpanjang sebanyak 15 orang, dan ini terjadi pada periode waktu padatkhususnya hari Senin. Agar kinerja sistem antrian ini menjadi optimal bank harus menambah satuteller untuk melayani nasabah yang akan melakukan transaksi terutama pada waktu padat agar antrianyang terjadi dalam sistem bisa berkurang dan waktu yang dibutuhkan nasabah juga tidak terlalu lama.

\section{Analisis Antrian Pelayanan Dengan Alternatif Dua Teller atau Multi Channel Single} Phase (M/M/S)

Berdasarkan pengamatan yang telah dilakukan pada penyetoran tunai khususnya waktu padatdengan menggunakan pelayanan satu teller nasabah yang datang belum bisa terlayani dengan baik,untuk itu digunakan alternatif dengan penambahan satu teller menjadi dua teller sehingga digunakanmodel Multi Channel Single Phase (M/M/S).

Model Multi Channel Single Phase atau dikenal dengan (M/M/S) merupakan model antrian jalurberganda dengan terdapat dua atau lebih jalur atau stasiun pelayanan yang tersedia untuk melayaninasabah yang datang. Asumsi bahwa pelanggan yang menunggu pelayanan membentuk satu jalur danakan dilayani pada stasiun pelayanan yang tersedia pertama kali.

Berikut tabel hasil perhitungan dengan menggunakan alternatif dua teller atau model MultiChannel Single Phase (M/M/S) adalah:

Tabel 2

Hasil Sistem Antrian M/M/S

\begin{tabular}{|c|c|c|c|c|c|c|c|c|}
\hline \multirow{2}{*}{ No } & \multirow{2}{*}{ Hari } & \multirow{2}{*}{ Tanggal } & \multicolumn{6}{|c|}{ Kinerja Sistem Antrian } \\
\hline & & & P0 & $\mathrm{P}$ & Ls & Ws & $\mathrm{Lq}$ & $\mathrm{Wq}$ \\
\hline 1 & Rabu & 01 November 2017 & 0,4125 & 0,42 & 1,01 & 0,0353 & 0,17 & 0,0061 \\
\hline 2 & Kamis & 02 November 2017 & 0,4902 & 0,34 & 0,77 & 0,0298 & 0,09 & 0,0035 \\
\hline 3 & Jumat & 03 November 2017 & 0,451 & 0,38 & 0,88 & 0,0314 & 0,13 & 0,0045 \\
\hline 4 & Senin & 06 November 2017 & 0,35044 & 0,48 & 1,25 & 0,0376 & 0,29 & 0,0087 \\
\hline
\end{tabular}

Sumber: Data hasil perhitungan 
Hasil perhitungan analisis model antrian berganda (M/M/S) terlihat bahwa dengan adanyapenambahan satu teller menjadi dua teller yang melayani nasabah, dapat disimpulkan bahwa sistemantrian yang ada pada PT Bank Syariah Mandiri Cabang Bungku sudah optimal jika menggunakan duateller pada waktu padat, karna untuk membandingkan tingkat kesibukan teller (p) khususnya pada hariSenin yaitu dari $85 \%$ menjadi $42 \%$ jika ada penambahan satu teller. Serta waktu terpajang yangdibutuhkan nasabah dalam sistem (Ws) yang awalnya 0,5 jam atau 30 menit menjadi 0,0376 atau 2 menit 15 detik.

Berdasarkan tabel di atas dapat dilihat bahwa waktu sibuk pada hari Senin jumlah nasabah yangmenunggu dalam sistem yaitu 16,50 dan ketika ada penambahan satu teller maka nasabah yangmenunggu dalam sistem berkurang menjadi 1,25 , ini menunjuan sudah optimal karna hanya 1 orangyang menunggu dalam sistem.

\section{KESIMPULAN DAN SARAN}

Kesimpulan

Berdasarkan hasil penelitian yang telah dipaparkan mengenai sistem antrian pelayanan pada PTBank Syariah Mandiri Cabang Bungku penulis dapat mengambil kesimpulan sebagai berikut:

1. Sistem antrian pelayanan yang terjadi pada PT Bank Syariah Mandiri Cabang Bungku dengan menggunakan model antrian M/M/1 pada waktu padat belum optimal.

2. Sistem antrian pelayanan nasabah pada PT Bank Syariah Mandiri Cabang Bungku dengan menambahkan teller menjadi dua teller yang beroperasi pada waktu padat atau menggunakanmodel antrian M/M/S tingkat pelayanannya sudah optimal.

Saran

Peneliti dapat memberikan saran untuk kebijakan perusahaan demi tercapai jumlah teller yangoptimal adapun saran yang diberikan antara lain:

1. Agar sistem antrian PT Bank Syariah Mandiri Cabang Bungku menjadi lebih optimal, ada baiknya pihak bank menyediakan nomor antrian untuk menjamin jika nasabah maupun tellerdalam melakukan transaksi.

2. Untuk mendapatkan pelayanan yang optimal maka pihak PT Bank Syariah Mandiri Cabang Bungku perlu penambahan satu tenaga kerja atau teller pada waktu padat.

\section{REFERENSI}

Bronson, R dan Haris, J. 1996. Teori dan Soal-Soal Operation Research. Edisi 3, Jilid 1-2, Seri Buku Schaum „S, Jakarta: Erlangga.

Gross dan Harris, 1994, The Queueing Systems, New York, McGraw-Hill, Inc.

Heizer, Jay dan Rander, Berry. 2005. Operation Management. Edisi 7, Buku 1. Jakarta: Selemba 4.

Prabowo, Fajar dan Bodroastuti, Tri. 2012. Penentuan Jumlah Teller yang Optimal Berdasarkan Metode Antrian (Studi Pada Bank Mega Cabang Pemuda Semarang. Jurnal Kajian Akuntansidan Bisnis.,Vol. 1, No. 1.

Taufik, Rustam. 2012. Analisis Penerapan Sistem Antrian Model M/M/S Pada PT Bank Negara Indonesia (Persero) Tbk. Kantor Cabang Pembantu Universitas Hasanuddin Makasar. SkripsiEkonomi, Fakultas Ekonomi, Jurusan Manajemen dan Bisnis, Universitas Hasanuddin :Makasar.

Siagian. 1987. Penelitian Operasional, Teori dan Praktek. Penerbit Universitas Indonesia., Jakarta. Jurnal Ekonomi.,Vol. 20, No. 20.

Sinalungga, 2008. Struktur Antrian, Pengantar Teknik Industri. Jakarta: Yogyakarta. 


\section{Hilda}

http:// www. Kajian pustaka. Com/2013/08/pengertian -sistem-antrian-dan-struktur antrian.html.

Tanggal akses 17 November jam 08.002017.

Taha, Hamdy A 1996. Operational Research An Introduction, Edisi 3, Jilid 2, Terjemahan Wirajaya, Binarupa, Angkasa, Jakarta.

Wahyudi, Ima. 2010. Penerapan Model Antrian Dua Fase (Studi Kasus di Rumah Sakit Mata "DR. Yap" Yogyakarta). Skripsi Sains, Fakultas Sains dan Teknologi, Universitas Islam NegeriSurabaya. Yogyakarta.

Wagner, H.1972. Principle Operations Research “With Applications To Managerial Decisions". London: Prentice-Hall. 